\title{
Chemotherapy for patients with multiple parasitic infections
}

\author{
P. L. CHIODINI* \\ Department of Clinical Parasitology, The Hospital for Tropical Diseases, London WC1E 6AU
}

SU M M A R Y

Multiple parasitic infections have become increasingly recognized as a result of improvements in laboratory diagnosis and a growing population of immunocompromised individuals. This review examines the principles of chemotherapy in groupings of multiple infections which are of particular clinical significance.

Key words: Multiple parasites, Onchocerca, Loa loa, intestinal helminths, schistosomiasis, malaria, AIDS, microsporidia, chemotherapy.

\section{INTRODUCTION}

Conventional medical training teaches medical students to make a single unifying diagnosis when analysing a clinical problem. Parasitology is an important exception to this rule and, especially in the tropics, it is common for an individual patient to harbour more than one parasite, sometimes in different organ systems or, especially in the case of the gastrointestinal tract, in the same one (Kang et al. 1998).

The approach to chemotherapy of multiple parasitic infections depends upon the following principles. (1) Precise diagnosis. At times this can be surprisingly difficult - in tropical areas diagnostic laboratory provision can vary from nil to sophisticated, but is most denied to those most affected by parasitic disease. This has led to syndromic treatment protocols and empirical, often broadspectrum, antiparasitic therapy. In affluent countries with well equipped laboratory services, lack of experience can still lead to difficulties in confirming the diagnosis outside reference centres, though external quality assessment schemes, e.g. UKNEQAS, have raised standards in recent years (Kettelhut et al. 1994). (2) The choice of narrow versus broad-spectrum agents is influenced by access to accurate laboratory diagnosis and by cost (both of diagnostic tests and the drugs required). (3) Whether an individual or the community is being treated. (4) The possibility of drug interaction if two or more antiparasitic agents are given simultaneously for multiple parasitic infections. (5) Where chemotherapy for one parasite might produce complications due to its action on another parasite present simultaneously. (6) In an individual case, which parasite predominates as the cause of disease.

* E-mail: peter.chiodini@uclh.org
Multiple parasitic infections can occur in many potential combinations but there are certain groupings which are of particular significance and are considered below.

\section{ONCHOCERCIASIS AND LOIASIS}

When ivermectin was under consideration as part of the Onchocerciasis Control Programme (OCP), its safety in community-based mass treatment programmes in geographical areas where the population harbours multiple filarial infections plus intestinal nematodes, was clearly critical to the acceptability and potential success of the mass treatment programme.

Richard-Lenoble et al. (1988) examined the safety and efficacy of ivermectin in patients with multiple filarial infections in Gabon. Seventeen patients with concomitant Loa loa and Onchocerca volvulus were studied. Other nematode infections found in this group were Mansonella perstans (five patients) and intestinal nematodes (16 patients). Each patient received ivermectin $200 \mu \mathrm{g} / \mathrm{kg}$ as a single dose. Ten days later, the mean Loa loa microfilarial count had fallen to twenty per cent of the mean level before treatment, and Onchocerca volvulus dermal microfilarial densities were only $2 \%$ of the pre-treatment values, whilst Mansonella perstans microfilarial counts were unaffected by ivermectin. By day 23, 15/15 with Ascaris infection had been parasitologically cured, but there had been no significant effect upon infections with Trichuris trichiura or Necator americanus. Ten (59\%) patients suffered pruritis one to five days post treatment, though neither antihistamines nor corticosteroids were required for symptomatic relief. However, the mean Loa loa microfilarial count was less than $300 / \mathrm{ml}$ of blood, so the tolerance of ivermectin with high 
microfilarial counts could not be determined by this study.

In 1995, the African Programme for Onchocerciasis Control (APOC) was launched, to develop community-based ivermectin treatment programmes in the nineteen Onchocerca volvulus endemic African countries outside the Onchocerca Control Programme in West Africa. Of the 19 participating countries, 12 have foci of Loa loa infection. Gardon et al. (1997) studied the incidence of serious adverse events following country-based ivermectin treatment in a part of Cameroon where onchocerciasis and loaisis were both endemic and explored the relationship between serious adverse events and pretreatment Loa loa microfilarial counts. Of 17877 patients treated, 20 developed serious non-neurological reactions, one of them fatal. Two patients developed serious neurological reactions, including coma, from which they had recovered after a month. Both had pre-treatment microfilarial counts in excess of $50000 / \mathrm{ml}$. It was possible to record the pretreatment microfilarial count for 5500 patients and the initial Loa loa microfilarial load was the main risk factor for the development of serious reactions; the risk increasing with microfilarial intensity. The association between microfilarial load and the occurrence of marked or serious reactions was significant above 8000 microfilaria/ml of blood. The occurrence of serious reactions was closely related to the Loa loa microfilarial load (odds ratio 114.7). The authors noted three previous cases of Loa loa encephalopathy related to ivermectin, also from Cameroon, and estimated the incidence of serious neurological reactions to be approximately 1.1 per 10000 people. The authors concluded that in areas where loiasis and onchocerciasis co-exist, the use of ivermectin should be carefully considered if the onchocerciasis does not present a serious public health problem locally. In other areas, where onchocerciasis is blinding or severely disabling, persons at risk need to be identified. Ivermectin appears able to provoke the passage of microfilariae of Loa loa into the cerebrospinal fluid (CSF) (Ducorps et al. 1995). A probable case of Loa loa encephalopathy related to ivermectin (PLERI) has been defined by four criteria: occurrence of a coma in a person who was previously healthy and has no other cause for the coma; onset of CNS symptoms and signs within 5 days of ivermectin therapy and progression to coma without remission; Loa loa microfilaraemia of greater than or equal to 10000 microfilariae/ml pre-treatment or greater than or equal to 1000 microfilariae per $\mathrm{ml}$ within two months after treatment; the presence of Loa loa microfilariae in the CSF.

Boussinesq et al. (1998) gave detailed descriptions of the PLERI cases noted by Gardon et al. (1997) which occurred in an area of Cameroon where $40-95 \%$ of the population had dermal microfilariae of Onchocerca and 10-33\% had Loa loa micro- filaraemia. Of 17877 persons treated with ivermectin $150 \mu \mathrm{g} / \mathrm{kg}$, two developed encephalopathy and twenty developed milder neurological reactions, with functional impairment requiring assistance to perform everyday domestic activities, but without disorders of consciousness or neurological signs. Boussinesq et al. (1998) reviewed a total of five PLERI cases. All occurred in young, previously healthy males. Initial symptoms, including fatigue, headache and joint pains, appeared on day one or two post-ivermectin. Disordered consciousness was usually manifest on day three or four. The patients were usually incontinent for several days, but the motor deficit was usually mild. Tendon reflexes were absent in three and brisk in one case; cog-wheeling was seen in two patients. All three individuals whose fundi were examined had retinal haemorrhages. Two patients died, one from gastrointestinal haemorrhage and one as a result of secondary bacterial infection. In both cases the diagnosis of PLERI was made too late for them to receive adequate therapy. In the three survivors, the clinical picture was most severe on days four or five, then showed progressive improvement, with almost full recovery one month after ivermectin therapy. Peripheral blood microfilarial counts were very high in all five PLERI cases and all had microfilariae in the CSF.

The major risk factor for PLERI is the peripheral blood microfilarial count (a level above 30000 microfilariae $/ \mathrm{ml}$ has been quoted as the risk threshold, (Chippaux et al. 1996) though a variety of co-factors has been suggested.

Treatment of PLERI involves good supportive care in hospital, antihistamines and/or corticosteroids, and early detection and treatment of secondary infection (Boussinesq et al. 1998). Prevention of PLERI depends upon identification of individuals at risk from a high microfilarial load; a difficult task without taking pre-treatment blood samples from the population in areas with a significant overlap of Onchocerca volvulus and Loa loa infections.

\section{INTESTINAL HELMINTHS}

In cases of mixed intestinal helminthic infections, the effect on the human host is influenced by the relative intensity of the infections present. For example, Sakti et al. (1999) studied cognitive functioning in a population of Indonesian school children in whom there was a $43 \%$ prevalence of helminth infection (24\% hookworm; $24 \%$ Trichuris trichiura; $8 \%$ Ascaris lumbricoides). Lower cognitive test scores were most apparent in children infected with hookworm rather than other helminths. The authors suggested this may be because the prevalence and/or intensity of infection with Ascaris or Trichuris were sufficiently low so as not to be responsible for significant morbidity or a public health problem. 
This contrasts with other studies where Trichuris infection has exerted a significant influence on cognitive test scores.

As hookworm, Ascaris and Trichuris all respond to single dose $(400 \mathrm{mg}$ ) albendazole therapy (Johnson \& Soave, 1999), in cases of mixed infection there is no clinical need to determine which of them is acting as the predominant pathogen either in an individual or community treatment setting. However, uptake of therapy is a major determinant of treatment success or failure, with a tendency for polypharmacy to result in reduced compliance. Thus, where the pattern of mixed infection dictates the use of two or more different drugs, e.g. praziquantel for schistosomiasis and albendazole for hookworm, a common delivery system should be deployed (Lwambo et al. 1999).

Intestinal nematodes and protozoa often coincide in infections of the gastrointestinal tract and Penggabean et al. (1998) examined the efficacy of albendazole on Trichuris and Giardia infections in rural Malaysia. Albendazole $400 \mathrm{mg}$ daily for three days was followed by cure rates of $91.5 \%$ for $T$. trichiura and $96.6 \%$ for G. intestinalis. Reynoldson et al. (1998) studied the effect of albendazole, $400 \mathrm{mg}$ daily for 5 days, on giardiasis and hookworm infection in an Aboriginal community in Western Australia. The prevalence of Giardia fell from 36.6\% pre-treatment to $12 \%$ between days 6 and $9,15 \%$ for days 10 to 17 and rose to $28 \%$ between days 18 and 30 . Hookworm prevalence fell from $76 \%$ prealbendazole to $2 \%$ between days $6-9$ and was zero by days $18-30$.

Community anthelminthic therapy is reviewed in detail in the chapter by Drake and Bundy in this supplement to which the reader is referred. There is still much work to do in studying the effects of treating geohelminth infection (multiple or single) in children and there will be no shortage of debate. For example, a recent Cochrane review concluded that public health investments in routine treatment of children in areas where helminths are common, based on the expectation of improved growth and learning, are not based on consistent or reliable evidence (Dickson et al. 2000).

SCH IS T OSOMIASIS

Recognition that co-infection with schistosomes and intestinal helminths was common in various parts of Africa (Adewunmi et al. 1993; Birrie, Erko \& Tedla 1994) has been followed by studies to assess the safety and efficacy of simultaneous combined mass treatment programmes.

Nokes et al. (1999) studied the effects of combined albendazole (400 mg single dose) and praziquantel $(60 \mathrm{mg} / \mathrm{kg}$ split dose $3 \mathrm{~h}$ apart) for the treatment of geohelminth infections and Schistosoma japonicum infections respectively. Neither drug affected the cure rate of the other drug and co-administration of these agents was both safe and effective. Beasley et al. (1999) demonstrated haematological benefits (reduced fall in haemoglobin) from single dose albendazole $(400 \mathrm{mg})$ and praziquantel $(40 \mathrm{mg} / \mathrm{kg})$ treatment compared to placebo in almost half of school children co-infected with geohelminths and Schistosoma haematobium in Tanga, Tanzania.

Schistosomiasis has also been associated with relapses of enteric fever (Gendrel et al. 1994), and persistent Salmonella bacteraemia in AIDS (Lambertucci, Rayes \& Gerspacher-Lara 1998); persistent Salmonella bacteraemia appears to exacerbate a pre-existing sub-clinical schistosomal glomerulopathy (Martinelli et al. 1992). Acute schistosomiasis has been reported to facilitate the development of Staphylococcus aureus liver abscesses (Lambertucci et al. 1998). Detailed discussion of these issues is outside the remit of this review, but effective treatment for schistosomiasis is required in each case.

\section{MALARIA}

Most infections with the human malaria parasites Plasmodium falciparum, $P$. vivax, $P$. ovale and $P$. malariae occur as single species. In cases where a patient harbours more than one species of malaria parasite, one or other species tends to be more numerous in the blood film, such that identification of the second species by microscopy can be very difficult, especially when young ring stages predominate in the blood film under examination. The advent of molecular techniques for the detection of malaria parasites has led to greater appreciation of the importance of mixed malarial infections. Brown et al. (1992) conducted a prospective comparison of microscopic diagnosis and PCR for the circumsporozoite gene for Plasmodium falciparum and for $P$. vivax in Thai soldiers. Of 137 consecutive cases of malaria, $3 / 32(9 \%)$ of microscopically diagnosed $P$. falciparum infections and 5/104 (5\%) of microscopically diagnosed $P$. vivax infections were found to be mixed by PCR. One case was diagnosed as mixed by microscopy and PCR. Pieroni et al. (1998) reported on 148 travellers with malaria as determined by PCR and microscopy, six $(4 \cdot 1 \%)$ of whom were shown to have mixed infections.

Treatment of mixed malarial infections is species dependent. In all cases the first priority is to treat the asexual erythrocytic stages as they are responsible for the malarial illness. If P. falciparum is present in the mixed infection it should be accorded priority as the most dangerous of the species infecting humans. The agents used are determined by the geographical origin of the parasite and thus its likely drug sensitivity/resistance profile, and the route of administration by the level of parasitaemia, severity of illness, the presence of complications and the 
ability to swallow oral medication in the patient concerned (WHO, 2000). Schizonticides effective against $P$. falciparum are usually effective against $P$. vivax, $P$. ovale and $P$. malariae. The asexual stages of mixed infections containing any combination of $P$. vivax, $P$. ovale or $P$. malariae can be treated with chloroquine (or quinine if the combination is thought to include chloroquine-resistant $P$. vivax). Mixed infections which include $P$. vivax or $P$. ovale require treatment directed against hypnozoites in the liver, to effect a radical cure and prevent relapse. The only agent currently marketed for this indication is the 8aminoquinoline, primaquine (Anon, 1991). The standard dosage regimen is $7.5 \mathrm{mg}$ twice daily for 14 days, but use of a higher dose (15 mg twice daily for 14 days) has been advocated following reports of treatment failure at the standard dose (Doherty et al. 1997). It is essential to check the glucose-6phosphate-dehydrogenase (G6PD) status of the patient prior to administering primaquine to avoid causing haemolysis in G6PD-deficient individuals.

\section{Malaria and helminths}

Tshikuka et al. (1996) studied 1100 children and mothers in Lubumbashi, Zaire to survey the relationship between parasitic infections and clinical syndromes to see whether single and/or multiple species infections were risk factors for the clinical syndromes concerned. They found no significant interactions between Plasmodium, Ascaris lumbricoides, Trichuris and hookworm and no evidence of synergism or antagonism between the parasites present in relation to the resulting disease. In such a situation, management of the parasitic infections detected can proceed by treating the most dangerous parasite first, though simultaneous treatment would also be acceptable in the absence of a risk of drug interaction. Fryauff et al. (1998) examined the effect of chloroquine or primaquine anti-malarial prophylaxis given for one year for malaria prevention on the presence of intestinal parasitic infections in a group of Javanese men in Irian Jaya. They found no significant change between baseline and endpoint in the type of species found, the mean number of species or ova per subject, the relative proportion of infections caused by these species or the occurrence of parasite free, single or multiple infections.

\section{Malaria and other protozoa}

Malarone $^{\circledR}$ (atovaquone/proguanil), a potent new antimalarial, also has activity against Toxoplasma and Pneumocystis carinii (via the atovaquone component in each case), so administration of this agent will have a wider antiparasitic effect than would be the case with more traditional antimalarials (such as quinine) which have a narrower spectrum of activity. Most agents used for antimalarial chemoprophylaxis (with the exception of proguanil which has some causal prophylactic activity) act as schizonticides to clear low grade asexual parasitaemia. Malarone ${ }^{\circledR}$ has both schizonticide and causal prophylactic activity (against pre-erythrocytic stages of all four species of human malaria parasites) but still lacks activity against hypnozoites, a property possessed only by primaquine and tafenoquine of the agents available or on clinical trial at present. Thus, if a person is challenged by multiple species of malaria parasites which include $P$. vivax or $P$. ovale, a risk of a delayed primary attack of malaria remains, unless primaquine or tafenoquine is used as a prophylactic agent.

In areas of high malaria endemicity, where there is a large proportion of individuals semi-immune to malaria, many people are asymptomatic but parasitaemic. In such a situation it can be difficult to decide whether or not malarial parasitaemia is contributing to the presenting clinical syndrome (e.g. fever and cough) where a mixed infection may be present. Keeping an open mind and looking, or treating if appropriate, for other causes, whilst also treating the malaria parasitaemia, presents a suitably pragmatic approach to this problem.

An association between falciparum malaria and Salmonella bacteraemia has been noted by some authors (Gopinath, Keystone \& Kain 1995; Ammah et al. 1999; Graham et al. 2000) but felt to be overestimated by others (Enwere et al. 1998). Full discussion of the issue is outside the scope of this review.

MULTIPLE PARASITIC INFECTIONS IN AIDS

The appearance of the Acquired Immune Deficiency Syndrome (AIDS) had a dramatic effect on parasitology. The previously obscure microsporidia were implicated in the causation of refractory diarrhoea in late stage AIDS (Hewan-Lowe et al. 1997; Kotler \& Orenstein, 1998) and cerebral toxoplasmosis, isosporiasis and cryptosporidiosis all came to prominence in this condition. Pneumonia due to Pneumocystis carinii (now classified amongst the fungi) became an indicator for an AIDS diagnosis. Given such an environment of diminished immunity it is not surprising that a variety of parasites appeared as co-infections and that treatment, maintenance therapy or prophylaxis directed against one parasite had an effect on other organisms present. Fortunately, this can be turned to the patient's advantage. Cotrimoxazole used for prophylaxis against Pneumocystis carinii also has prophylactic activity against Toxoplasma gondii and is effective for the treatment and maintenance therapy of Isospora belli and Cyclospora cayetanensis. However, there may be concerns arising from the use of cross-reactive antiparasitic drugs. For example, atovaquone, a second line agent for the treatment of toxoplasmosis (Fung \& Kirschenbaum, 1996; Katlama et al. 1996) 
or the prevention and treatment of pneumonia due to Pneumocystis carinii (Castro, 1998; El-Sadr et al. 1998), has good antimalarial activity, but Plasmodium falciparum infections readily recrudesce when treated with atovaquone alone (Chiodini et al. 1995), hence its use in combination with proguanil as the product Malarone ${ }^{\circledR}$, when it is used against malaria. If atovaquone is deployed against Toxoplasma or Pneumocystis in individuals exposed to frequent malaria challenge, there is a potential to encourage the development of atovaquone-resistant Plasmodium falciparum.

Nowhere is the issue of unequal access to precise laboratory diagnosis and targetted therapy more evident than in the investigation of AIDS-associated diarrhoea. Where the techniques are available, more than $80 \%$ of diarrhoea cases in patients with HIV/AIDS can be attributed to a specific enteropathogen and Cryptosporidium parvum, Isospora belli, Cyclospora cayetanensis and the microsporidia explain at least $50 \%$ of cases of persistent diarrhoea (Farthing, Kelly \& Veitch 1996).

Albendazole has an unusually wide spectrum for an antiparasitic drug, with clinically useful activity against larval cestodes (cysticercosis, hydatid disease), Giardia, some microsporidia (Molina et al. 1998), intestinal nematodes and lymphatic filariasis. This wide spectrum helps compliance with treatment in a condition in which multiple drug therapy is common. Its activity against the microsporidian Enterocytozoon intestinalis, Giardia and intestinal nematodes is particularly useful in the management of AIDS-associated diarrhoea in situations in situations where precise laboratory diagnosis may not be possible. For example, Kelly et al. (1996) examined the effect of a 2 week, high dose (800 mg twice daily) albendazole course versus placebo on persistent diarrhoea of more than three weeks' duration in 174 HIV seropositive patients in Zambia. No gastrointestinal investigations were performed. The patients who received albendazole had diarrhoea on $29 \%$ fewer days than the placebo group $(P<0 \cdot 0001)$ in the two weeks after therapy and the therapeutic benefit of albendazole was maintained over six months, supporting its use as empirical therapy in the context described.

One of the most useful benefits from treating coinfections in AIDS has come not from an antiparasitic drug, but from antiviral chemotherapy directed against the underlying HIV infection. The introduction of combination highly active antiretroviral therapy (HAART) has improved the ability of patients to control AIDS-associated opportunistic infections. For example, Conteas et al. (1998) looked at modification of the clinical course of intestinal microsporidiosis due to Enterocytozoon bieneusi in AIDS patients according to their immune status and anti-retroviral therapy. Decreased time to clearance of $E$. bieneusi was associated with per- ipheral blood CD4 cell counts greater than or equal to $100 \mathrm{~mm}^{3}$, the use of two or more antiretroviral drugs, and use of a protease inhibitor.

\section{CONCLUSIONS}

There is likely to be increasing recognition of the presence and importance of multiple parasitic infections in human hosts as more sensitive, highly sophisticated laboratory techniques for their detection become more readily available and as the population of immunocompromised individuals increases.

Broad-spectrum agents, or single delivery systems for administration of multiple agents, will form the mainstay of mass treatment programmes for intestinal parasites conducted without prior laboratory diagnosis. Caution must always be exercised in planning large scale antiparasitic treatment programmes, whatever the parasite or organ system involved, to avoid the potential for adverse events related to drug activity on concomitant infections.

\section{REFERENCES}

ADEWUNMI, C. O., GEBREMEdHIN, G., BECKER, W., OluRunMola, F. O., DORFLER, G. \& ADENWUNMI, T. A. (1993). Schistosomiasis and intestinal parasites in rural villages in southwest Nigeria: an indication for expanded programme on drug distribution and integrated control programme in Nigeria. Tropical Medicine and Parasitology 44, 177-180.

AMMAh, A., NKUO-AKENJi, T., NDIP, R. \& DEAS, J. E. (1999). An update on concurrent malaria and typhoid fever in Cameroon. Transactions of the Royal Society of Tropical Medicine and Hygiene 93, 127-129. ANON (1991). Primaquine. In Therapeutic Drugs (ed. Dollery, C.) Edinburgh: Churchill Livingstone BEASLEY, N. M. R., TOMKINS, A. M., HALl, A., KiHAMia, C. M., LORRI, W., NDUMA, B., ISSAE, W., NOKES, C. \& BUNDY, D. A. P. (1999). The impact of population level deworming on the haemoglobin levels of schoolchildren in Tanga, Tanzania. Tropical Medicine and International Health 4, 744-750.

BIRRIE, H., ERKO, B. \& TEDLA, S. (1994). Intestinal helminthic infections in the southern Rift Valley of Ethiopia with special reference to schistosomiasis. East African Medical Fournal 71, 447-452.

BoussinesQ, M., GARDON, J., GARDON-WENDEL, N., Kamgno, J., NGOUmou, P. \& Chippaux, J.-P. (1998). Three probable cases of Loa loa encephalopathy following ivermectin treatment for onchocerciasis. American Yournal of Tropical Medicine and Hygiene 58, 461-469.

Brown, A. E., Kain, K. C., PIPITHKUl, J. \& Webster, H. K. (1992). Demonstration by the polymerase chain reaction of mixed $P$. falciparum and $P$. vivax infections undetected by conventional microscopy. Transactions of the Royal Society of Tropical Medicine and Hygiene 86, 609-612.

Castro, M. (1998). Treatment and prophylaxis of Pneumocystis carinii pneumonia. Seminars in Respiratory Infection 13, 296-303. 
ChiOdini, P. L., CONLON, C. P., HUTChinson, D. B., FARQUhar, J. A., HALl, A. P., PETO, T. E. \& BIRLEY, H. (1995). Evaluation of atovaquone in the treatment of patients with uncomplicated Plasmodium falciparum malaria. Fournal of Antimicrobial Chemotherapy 36, 1073-1078.

Chippaux, J. P., BOUSSINESQ, M., GARDON, J., GARDONWENDEL, N. \& ERNAULD, J. C. (1996). Severe adverse reaction risks during mass treatment with ivermectin in loiasis-endemic areas. Parasitology Today 12, 448-450.

CONTEAS, C. N., BERLin, O. G. W., SPECK, C. E., PANDHUMAS, S. S., LARIVIERE, M. J. \& FU, C. (1998). Modification of the clinical course of intestinal microsporidiosis in acquired immunodeficiency syndrome patients by immune status and anti-human immunodeficiency virus therapy. American Fournal of Tropical Medicine and Hygiene 58, 555-558.

DICKSON, R., AWASTHI, S., DEMELLWEEK, C. \& Williamson, P. (2000). Anthelmintic drugs for treating worms in children: effects on growth and cognitive performance (Cochrane Review) In The Cochrane Library Issue 4. Oxford, Update Software DOHERTY, J. F., DAY, J. H., WARHURST, D. C. \& CHIODINI, P. L. (1997). Treatment of Plasmodium vivax malariatime for a change? Transactions of the Royal Society of Tropical Medicine and Hygiene 91, 76.

DUCORPS, M., GARDON-WENDEL, N., RANQUE, S., NDONG, W., BOUSSINESQ, M., GARDON, J., SCHNEIDER, D. \& Chippaux, J. P. (1995). Effets secondaires du traitement de la loase hypermicrofilaremique par l'ivermectine. Bulletin de la Société de Pathologie Exotique 88, 105-112.

EL-SADR, W. M., MURPHY, R. L., YURIK, T. M., LUSKINHAWK, R., CHEUNG, T. W., BALFOUR, H. H., ENG, R., HOOTON, T. M., KERKERING, T. M., SCHUTZ, M., VAN DER HORST, C. \& HAFNER, R. (1998). Atovaquone compared with dapsone for the prevention of Pneumocystis carinii pneumonia in patients with HIV infection who cannot tolerate trimethoprim, sulfonamides or both. Community Program for Clinical Research on AIDS and the AIDS Clinical Trials Group. New England Fournal of Medicine 339, 1889-1895.

ENWERE, G., VAN HENSBROEK, M. B., ADEGBOLA, R., PALMER, A., ONYIORA, E., WEBER, M. \& GREENWOOD, B. (1998). Bacteraemia in cerebral malaria. Annals of Tropical Paediatrics 18, 275-278.

FARThiNG, M. J. G., KELly, M. P. \& Veitch, A. M. (1996).

Recently recognised microbial enteropathies and HIV infection. Fournal of Antimicrobial Chemotherapy 37, Suppl. B, 61-70.

FRYAUFF, D. J., PRODJODIPURO, P., BASRI, H., JONES, T. R., MOUZIN, E., Widjaja, H. \& SUbianto, B. (1998).

Intestinal parasite infections after extended use of chloroquine or primaquine for malaria prevention. Fournal of Parasitology 84, 626-629.

FUnG, H. B. \& KiRSChenbaum, H. L. (1996). Treatment regimens for patients with toxoplasmic encephalitis. Clinical Therapy 18, 1037-1056 (discussion 1036).

GARDON, J., GARDON-WENDEL, N., DEMANGA-NGANGUE, Kamgno, J., Chippaux, J.-P. \& BoussinesQ, M. (1997). Serious reactions after mass treatment of onchocerciasis with ivermectin in an area endemic for Loa loa infection. Lancet 350, 18-22.
GENDREL, D., KOMBILA, M., BEAUDOIN-LEBLEVEC, G. \& RICHARD-LENOBLE, D. (1994). Nontyphoidal salmonellal septicemia in Gabonese children infected with Schistosoma intercalatum. Clinical Infectious Diseases 18, 103-105.

GOPINATH, R., KEYSTONE, J. S. \& KAIN, K. C. (1995). Concurrent falciparum malaria and Salmonella bacteremia in travelers: report of two cases. Clinical Infectious Diseases 20, 706-708.

GRaham, S. M., WAlsh, A. L., MOLyneUX, E. M., Phiri, A. J. \& Molyneux, M. E. (2000). Clinical presentation of non-typhoidal Salmonella bacteraemia in Malawian children. Transactions of the Royal Society of Tropical Medicine and Hygiene 94, 310-314.

HEWAN-LOWE, K., FURLONG, B., SIMS, M. \& SCHWARTZ, D. A. (1997). Coinfection with Giardia lamblia and Enterocytozoon bieneusi in a patient with acquired immunodeficiency syndrome and chronic diarrhea. Archives of Pathology and Laboratory Medicine 121, 417-422.

JOHNSON, E. K. \& SOAVE, R. (1999) Antiparasitic agents In Infectious Diseases (ed. Armstrong DA \& Cohen, J) London, Mosby.

KANG, G., MATHEW, M. S., RAJAN, D. P., DANiEL, J. D., Mathan, M. M., Mathan, V. I. \& MUliyil, J. P. (1998). Prevalence of intestinal parasites in rural Southern Indians. Tropical Medicine and International Health 3, $70-75$.

Katlama, C., MOUThon, B., Gourdon, D., LApierRe, D. \& Rousseau, F. (1996). Atovaquone as long-term suppressive therapy for toxoplasmic encephalitis in patients with AIDS and multiple drug intolerance. Atovaquone Expanded Access Group. AIDS 10, 1107-1112.

Kelly, P., LUNGU, F., KEANe, E., BAGGaley, R., KaZembe, F., POBEe, J. \& FARTHiNG, M. (1996). Albendazole chemotherapy for treatment of diarrhoea in patients with AIDS in Zambia: a randomised double blind controlled trial. British Medical fournal 312, 1187-1191.

KeTtLeHUT, M., EDWARDS, H., MOODY, A. H \& CHIODINI, P. L. (1994). The United Kingdom National External Quality Assessment Scheme for Parasitology. Medical Microbiology Letters 3, 203-208.

KOTLER, D. P. \& ORENSTEIN, J. M. (1998). Clinical syndromes associated with microsporidiosis. Advances in Parasitology 40, 321-349.

LAMbertuCCI, J. R., RAYES, A. A. M. \& GERSPACHER-LARA, R. (1998). Salmonella-S. mansoni association in patients with acquired immunodeficiency syndrome. Revista do Instituto de Medicina Tropical de Sao Paolo 40, 233-235.

LAMBERTUCCI, J. R., RAYES, A. A. M., SERUFO, J. C., GERSPACHER-LARA, R., BRASILEIRO-FILHO, G., TEIXEIRA, R., ANTUNES, C. M. F., GOES, A. M. \& COELHO, P. M. Z. (1998). Schistosomiasis and associated infections. Memorias do Instituto Oswaldo Cruz 93, 135-139.

LWAMBo, N. J. S., SIZA, J. E., BROOKER, S., BUNDY, D. A. P. \& GUYATT, H. (1999). Patterns of concurrent hookworm infection and schistosomiasis in schoolchildren in Tanzania. Transactions of the Royal Society of Tropical Medicine and Hygiene 93, 497-502. MARTINElli, R., PEREIRA, L. J. C., BRITO, E. \& ROCHA, H. (1992). Renal involvement in prolonged Salmonella 
bacteremia: the role of schistosomal glomerulopathy.

Revista do Instituto de Medicina Tropical de Sao Paulo 34, 193-198.

molina, J. M., Chastang, C., GOGUel, J., Michiels, J. F., SARFATI, C., DESPORTES-LiVAGE, I., HORTON, J., DEROUIN, F. \& MODAI, J. (1998). Albendazole for treatment and prophylaxis of microsporidiosis due to Encephalitozoon intestinalis in patients with AIDS: a randomized double-blind controlled trial. Fournal of Infectious Diseases 177, 1373-1377.

Nokes, C., McGarvey, s. T., Shiue, L., WU, G., WU, H., BUNDY, D. A. P. \& OLDS, G. R. (1999). Evidence for an improvement in cognitive functioning following treatment of Schistosoma japonicum infection in Chinese primary schoolchildren. American Fournal of Tropical Medicine and Hygiene 60, 556-565.

PENGGABEAN, M., NORHAYATI, M., OOTHUMAN, P. \& FAтмAн, M. S. (1998). Efficacy of albendazole in the treatment of Trichuris trichiura and Giardia intestinalis infection in rural Malay communities. Medical fournal of Malaysia 53, 408-412.

PIERONI, P., Mills, C. D., OHRT, C., HARRINGTON, M. A. \& KaIN, K. C. (1998). Comparison of the ParaSight-F test and the ICT Malaria $P f$ test with the polymerase chain reaction for the detection of Plasmodium falciparum malaria in travellers. Transactions of the Royal Society of Tropical Medicine and Hygiene 92, 166-9.
REYNOLDSON, J. A., BEHNKE, J. M., GRACEY, M., HORTON, R. J., SPargo, R., HOPKins, R. M., COnstantine, C. C., GILBERT, F., STEAD, C., HOBBS, R. P. \& THOMPSON, R. C. A. (1998). Efficacy of albendazole against Giardia and hookworm in a remote Aboriginal community in the north of Western Australia. Acta Tropica 71, $27-44$.

RICHARD-LENOBle, D., KOMBILA, M., RUPP, E. A., PAPPAyliou, E. S., GoXotTe, P., NGUiRi, C. \& AZIZ, M. A. (1998). Ivermectin in Loiasis and Concomitant Onchocerca volvulus and Mansonella perstans infections. American Fournal of Tropical Medicine and Hygiene 39, 480-483.

SAKTi, H., NOKES, C., HERTANTO, W. s., HENDRATNO, S., HALl, A., BUNDY, D. A. P. \& SATOTo. (1999). Evidence for an association between hookworm infection and cognitive function in Indonesian school children. Tropical Medicine and International Health 4, 322-334.

TSHIKUKA, J. G., SCOTT, M. E., GRAY-DONALD, K. \& KAluMBa, O. N. (1996). Multiple infection with Plasmodium and helminths in communities of low and relatively high socio-economic status. Annals of Tropical Medicine and Parasitology 90, 277-293. WORLD HEALTH ORGANizATION (2000). Severe falciparum malaria [Severe and Complicated Malaria, third edition]. Transactions of the Royal Society of Tropical Medicine and Hygiene 94, suppl 1, S1-S90 